Е. И. Нефедьева

Байкальский государственный университет, г. Иркутск, Российская Федерация

С. И. Кудрявцев

Байкальский государственный университет, г. Иркутск, Российская Федерация

\title{
СОЦИАЛЬНО-ЭКОНОМИЧЕСКАЯ АДАПТАЦИЯ ГРАЖЖДАН ПОЖИЛОГО ВОЗРАСТА И ИНВАЛИДОВ \\ В СТАЦИОНАРНЫХ УСЛОВИЯХ СОЦИАЛЬНОГО ОБСЛУЖИВАНИЯ (НА ПРИМЕРЕ ОГБУСО «НОВО-ЛЕНИНСКИЙ ДОМ-ИНТЕРНАТ ДЛЯ ПРЕСТАРЕЛЫХ И ИНВАЛИДОВ»)
}

АНнотАция. В статье представлены результаты социологического исследования проблемы социальной и экономической адаптации пожилых и инвалидов в стационарных условиях социального обслуживания. Изучение проведено на примере ОГБУСО «Ново-Ленинский дом-интернат для престарелых и инвалидов». Тенденции, выявленные в одном из стационарных учреждений социального обслуживания пожилых и инвалидов, распространены во всех аналогичных учреждениях. Проводится сравнение адаптации у вновь поступающих на обслуживание с постоянно проживающими доме-интернате. Исследование социальной адаптации пожилых и инвалидов к условиям дома-интерната проводится по различным аспектам. Рассмотрены основные причины поступления пожилых граждан в дом-интернат; проблемы и последствия их социальной адаптации в учреждении; оценка условий проживания и социальной помощи, оказываемой учреждением; характер взаимоотношений между проживающими и персоналом; инновационные технологии стационарного социального обслуживания, применяемые в учреждении; возможности совершенствования социальной адаптации пожилых и инвалидов в домах-интернатах. Изучение поставленной проблемы предполагает комплексный характер исследования, включающий рассмотрение мнения двух разных сторон: проживающих в интернате и персонала учреждения. Кроме этого, исследование носит мониторинговый характер и позволяет сравнить результаты опроса 2017 г. с аналогичными данными 2005 г.

кЛючЕВЫЕ СЛОВА. Социальное обслуживание; стационарное социальное обслуживание; дом-интернат; граждане пожилого возраста; социальная адаптация; социальные услуги.

ИНФОРМАЦИЯ О СТАТЬЕ. Дата поступления 24 июля 2017 г.; дата принятия к печати 11 октября 2017 г.; дата онлайн-размещения 25 октября 2017 г.

ФИНАНСИРОВАНИЕ. Работа выполнена при финансовой поддержке Федерального государственного бюджетного учреждения «Российский фонд фундаментальных исследований» на реализацию в 2017 г. научного проекта № 17-03-00477/17 «Влияние идей патернализма на поведенческие стратегии: исследование практик социального иждивенчества и социального паразитизма отдельных категорий населения» (протокол № 4(186) от 15 марта 2017 г.).

Ye. I. Nefedyeva Baikal State University, Irkutsk, Russian Federation

S. I. Kudryavtsev Baikal State University, Irkutsk, Russian Federation

\section{SOCIAL AND ECONOMIC ADAPTATION OF THE AGED CITIZENS AND DISABLED IN STATIONARY ENVIRONMENT OF SOCIAL SERVICE (IN TERMS OF «NOVO-LENINO CARE HOME FOR THE AGED AND DISABLED»)}

ABSTRACT. The article presents the results of sociological investigation of problems of social and economic adaptation of the aged and disabled in stationary environment of

(ㄷ Е. И. Нефедьева, С. И. Кудрявиев, 2017

\section{Baikal Research Journal}


social service. The investigation is carried out in terms of «Novo-Lenino Care Home for the Aged and Disabled». The tendencies identified in one of the stationary institutions of social service for the aged and disabled are spread in all analogical institutions. A comparison is made of new people going into service with those living constantly in the care home. Investigation of the aged and disabled adaptation to the care home environment is carried out in terms of various aspects. The article examines the causes of enrolling the aged people to the care home; the problems and consequences of their social adaptation in the house; evaluation of the living terms and the social aid offered by the house; the character of interrelations between the residents and the personnel; innovative technologies of the stationary social service used in the house; possibilities of mastering social adaptation of the aged and disabled in care houses. The study of the problem set assumes a complex character of the investigation including consideration of the opinions of the two sides: of those living in the care house and of the personnel of the house. Besides, investigation bears a monitoring character and allows to compare the results of the 2017 polling with the analogous 2005 data.

KEYWORDS. Social service; stationary social service; care house; aged citizens; social adaptation; social services.

ARTICLE INFO. Received July 24, 2017; accepted October 11, 2017; available online October 25, 2017.

ACKNOWLEDGEMENTS. The work is done with financial support from the Federal State Budgetary Institution «Russian Fund of Fundamental Research» for implementing in 2017 the scientific project № 17-03-00477/17 «The impact of paternalism ideas on behavioral strategy: investigation of practices of social sponging and social parasitism of certain population categories» (protocol № 4(186) of March 15, 2017).

Рассмотрим проблему социально-экономической и психологической адаптации пожилых и инвалидов к условиям домов-интернатов на примере ОГБУ СО «Ново-Ленинский дом-интернат для престарелых и инвалидов», основываясь на проведенном социологическом исследовании среди получателей услуг и персонала учреждения ${ }^{1}$.

Изучение поставленной проблемы предполагает комплексный характер исследования, включающий рассмотрение мнения двух разных сторон: проживающих в интернате и персонала учреждения. Кроме этого, исследование носит мониторинговый характер и позволяет сравнить результаты опроса 2017 г. с аналогичными данными 2005 г. [1;2].

Методика исследования включает использование: 1) метода анкетного опроса пожилых и инвалидов, проживающих в учреждении и являющихся получателями социальных услуг; 2) метода экспертного полустандартизованного интервью работников учреждения, занимающимися вопросами социальной адаптации обслуживаемых пожилых и инвалидов.

Объектом исследования выступают престарелые и инвалиды дома-интерната, а также персонал учреждения (психологи, медицинские работники и специалисты по социальной работе).

Предмет исследования - это условия проживания и проблемы социально-экономической и психологической адаптации проживающих в доме-интернате.

Цель исследования - разработка предложений по улучшению качества социального обслуживания, в т.ч. социальной адаптации, граждан пожилого возраста и инвалидов в стационарных условиях.

Рассмотрим, какие на сегодняшний день распространены основные причины поступления в дома-интернаты пожилых и инвалидов, отличаются ли эти причины от тех, которые были несколько лет назад. Основываясь на результатах экс-

${ }^{1}$ Об основах социального обслуживания граждан в Российской Федерации [Электронный ресурс] : федер. закон от 28.12.2013 г. № 442-ФЗ // СПС «КонсультантПлюс».

\section{Baikal Research Journal}

электронный научный журнал Байкальского государственного университета 
пертного интервью персонала и анкетирования проживающих Ново-Ленинского дома-интерната, можно утверждать, что при поступлении в дом-интернат присутствует, как правило, не одна о причина. Причины сопровождают друг друга, это и состояние здоровья, и плохое отношение родственников, и др. [3]

На первом месте находится такая причина, как «состояние здоровья». По оценке большинства экспертов из числа персонала Ново-Ленинского дома-интерната для престарелых и инвалидов (табл. 1), данная причина является основной при поступлении одиноких пожилых и инвалидов в дома-интернаты. С мнением персонала учреждения коррелируют данные анкетирования проживающих, среди которых абсолютное большинство указывают на основную причину поселения в доме престарелых - это «ухудшающееся состояние здоровья, одиночество и, как следствие, невозможность самообслуживания» (что отмечают 44,1 \% респондентов из числа пожилых и инвалидов учреждения).

Причины поступления граждан пожилого возраста и инвалидов в стационарные учреждения социального обслуживания, \%*

\begin{tabular}{|l|r|r|}
\hline \multicolumn{1}{|c|}{ Варианты ответов } & 2005. & \multicolumn{1}{c|}{2017} \\
\hline Состояние здоровья & 48,4 & 91,7 \\
\hline Отказ родственников & 45,2 & 50,0 \\
\hline Желание самого пожилого человека переехать от своих детей & 41,9 & 33,0 \\
\hline $\begin{array}{l}\text { Желание самого пожилого человека переехать из-за трудности } \\
\text { проживания одному в доме }\end{array}$ & 54,8 & 58,3 \\
\hline Отсутствие постоянного нормального места жительства & 19,4 & 50,0 \\
\hline
\end{tabular}

" Выбор допускал несколько вариантов ответа.

Причиной, находящейся на втором месте, является «желание самого пожилого (инвалида) переехать на постоянное место жительство, вследствие проживания в одиночестве и отсутствия близких родственников», а значит трудности самообеспечения, самообслуживания. На третьем месте по результатам экспертного интервью отмечается такая причина, как «отказ родственников» (что отметили половина опрошенных специалистов), а также «отсутствие постоянного норлального места жительства и отказ родственников от пожилого человека» (что поддерживают $25 \%$ участвующих в анкетировании проживающих дома-интерната). Далее следует «желание пожилого человека уехать от своих близких", с которыми он проживал совместно. Как в данном случае высказываются сами пожилые: «стал обузой для внуков и детей» (для $5,9 \%$ проживающих). И $25 \%$ респондентов из числа пожилых и инвалидов домаинтерната указали другие причины: «ощущение одиночества» (8,8 \% проживающих), «ушел добровольно», «неколу было ухаживать», «стал старыл», «нужна полощь посторонних», «переезд из одного дола-интерната в другой».

Если сопоставить результаты опросов 2017 и 2005 гг., то можно отметить следующие изменения. Значительно увеличена главная причина поселения одиноких пожилых и инвалидов в дом-интернат для постоянного проживания «состояние здоровья». Несколько участились случаи «отказов родственников» от своих престарелых или болеющих родителей, других членов семьи. Напротив, можно наблюдать уменьшение проявления такой причины, как «желание самого пожилого человека переехать от своих детей» и «отсутствие постоянного места жительства», что частично можно объяснить снижением остроты жилищной проблемы за последние десятилетия.

\section{Baikal Research Journal}


Важно рассмотреть проблемы, связанные с адаптацией проживающих $к$ условиям домов-интернатов, с точки зрения самих проживающих и персонала данных учреждений. Сравнение проведем за два периода исследования -2005 и 2017 гг. (табл. 2).

Основной проблемой проживающих и поступающих, по мнению респондентов-экспертов, является социально-психологический климат в отношениях друг с другом. Специалисты, участвующие в опросе в 2017 г., отметили, что наиболее ярко выражена данная проблема у «вновь поступающих на социальное обслуживание» в дом-интернат (100 \% мнений экспертов), нежели у постояльцев (50\%). По результатам опроса 2005 г. данная проблема не так ярко выражена $(60,9 \%$ и 76,8 \% соответственно). Проблемы «взаимоотношений персонала с проживающими» отмечаются в 2017 г. в 16,7 \% случаев, а в 2005 г. - в 10,9 \% случаев.

Такая проблема, как «бытовые условия» для проживающих и для поступающих в дом-интернат, отмечена специалистами дома-интерната в 2005 г. По данным экспертного интервью 2017 г., бытовые условия являются проблемой, но исключительно для вновь поступающих на стационарное обслуживание (по мнению 27,3 \% специалистов учреждения). С бытовыми проблемами тесно связана проблема качества питания. По результатам исследования 2017 г. 41,7 \% опрошенных специалистов считают, что качество питания также является проблемой для поступающих на обслуживание, а для проживающих эта проблема уже не является такой острой $(9,1 \%)$, т.к. формируется некая привычка к режиму и стандарту питания в доме-интернате. Проблема качества питания была выражена и по результатам исследования 2005 г., что отметили 28,1 и 7,3 \% соответственно.

Таблица 2

Дифференциация проблем, возникающих у вновь поступающих в дом-интернат для престарелых и инвалидов и у постоянно проживающих, \%

\begin{tabular}{|l|r|r|r|r|}
\hline \multicolumn{1}{|c|}{ Перечень проблем } & \multicolumn{3}{|c|}{ Поступающие } & \multicolumn{2}{|c|}{ Проживаюие } \\
\cline { 2 - 5 } & 2005 & 2017 & \multicolumn{1}{c|}{2005} & 2017 \\
\hline Бытовые условия & 17,1 & 27,3 & 14,6 & - \\
\hline Качество медицинского обслуживания & 3,7 & 18,2 & 6,1 & 25,0 \\
\hline Качество питания & 7,3 & 9,1 & 28,1 & 41,7 \\
\hline $\begin{array}{l}\text { Взаимоотношение с медицинским персоналом и соци- } \\
\text { альными работниками }\end{array}$ & 4,9 & - & 10,9 & 16,7 \\
\hline Социально-психологический климат среди пациентов & 60,9 & 100,0 & 76,8 & 50,0 \\
\hline Проведение свободного времени & 3,7 & 9,1 & 9,7 & 25,0 \\
\hline $\begin{array}{l}\text { Возможность реализации своих интересов, профессио- } \\
\text { нальных навыков }\end{array}$ & 7,3 & - & 9,7 & 50,0 \\
\hline
\end{tabular}

Кроме этого, 25 \% специалистов опроса 2017 г. отметили, что «качество ме дицинского обслуживания» тоже является проблемой для проживающих и для поступающих $(18,2 \%)$, в меньшей степени данную проблему отметили эксперты исследования 2005 г. На качество медицинского обслуживания по мнению экспертов обижаются не так много проживающих в 2005 г.: среди вновь поступающих таких $3,7 \%$ и среди проживающих $6,1 \%$, что связано в первую очередь с недостатком медицинских препаратов.

Вторая из категории проблем после реализации психофизиологических потребностей - это "реализация интересов и проведение досуга». У постоянно проживающих в доме-интернате возникает проблема с «возложностяли реализации своих интересов, профессиональных навыков» (50 \% мнений экспертов), «про-

\section{Baikal Research Journal}

электронный научный журнал Байкальского государственного университета 
ведения свободного времени» (25 \%) по данным опроса 2017 г., что не было так выражено 12 лет назад $(9,7 \%)$.

Необходимо отметить, что более требовательными в отношении условий содержания в домах-интернатах являются давно проживающие пожилые и инвалиды, нежели новички.

Остановимся на рассмотрении не только проблем проживания и социально-психологической адаптации обслуживаемых домов-интернатов, но и на последствиях, к которым данные проблемы приводят (табл. 3) [4].

Так, среди опрошенных специалистов больше половины считают, что наиболее острыми последствиями являются «нарушения правил проживания в учреждении» $(83,3$ \%), и «ссоры выяснение отношений с другими пациентали» $(83,3$ \%), треть респондентов отметили, что «регулярные скандалы с медицинскил персоналол и социальныли работниками» тоже являются острыми последствиями. Были получены и иные мнения, например: «недостаток внилания проживающим от персонала».

Таблица 3

Последствия, порождаемые проблемами социальной адаптации пожилых и инвалидов в условиях дома-интерната, \%

\begin{tabular}{|l|r|r|}
\hline \multicolumn{1}{|c|}{ Варианты ответов } & \multicolumn{1}{c|}{2005} & \multicolumn{1}{c|}{2017} \\
\hline Добровольный уход из дома престарелых & 9,1 & - \\
\hline Наказания со стороны администрации и персонала дома престарелых & 13.6 & - \\
\hline Регулярные скандалы с персоналом учреждения & 13,6 & $33,3 \%$ \\
\hline Ссоры, выяснение отношений с другими пациентами & 81,8 & $83,3 \%$ \\
\hline Нарушения правил проживания в учреждении & 68,2 & $83,3 \%$ \\
\hline Попытки самоубийства & 4,5 & - \\
\hline
\end{tabular}

По результатам опроса 2005 г. одной из основных последствий, вытекающих из различных рассмотренных выше проблем учреждения, по мнению опрошенных специалистов, является «выяснение отношений между проживаюшили в учреждении» $(81,8$ \%). На втором месте $(68,2$ \%) стоит последствие, вызванное нарушением правил проживания. Результаты аналогичны результатам исследования 2017 г.

Такие последствия, как «наказание со стороны адлинистрации и персонала», «добровольный уход и попытки салоубийства», то данные последствия не указаны респодентами-экспертами в 2017 г., в отличие от данных исследования в 2005 г.

Кроме того, наиболее частыми случаями, вызывающими самые острые проблемы в домах-интернатах, являются «злоупотребление спиртныли напитками среди проживающих и как следствие ссоры и драки между ними». Также это «несовместилость характеров у проживающих совместно в колнатах (не уживаются)». В некоторых случаях отмечается «нарушение правил проживания, связанное с курениел в комнатах (противопожарные условия)».

$\mathrm{C}$ каким контингентом дома престарелых по демографическим и социальным критериям возникают наибольшие проблемы? По словам специалистов-экспертов, это, прежде всего: «проживающие с алкогольной зависимостью; пожилые в возрасте более 80-90 лет; проживающие из числа молодых инвалидов с активной жизнедеятельностью».

Какие действия со стороны администрации и персонала дома престарелых могут изменить ситуацию в лучшую сторону? Как отметили специалисты дома-интерната, являющиеся участниками экспертного опроса, меры могут быть разными. Прежде всего, это «более чуткое отношение $к$ получателям услуг со стороны

\section{Baikal Research Journal}

электронный научный журнал Байкальского государственного университета 
работников интерната; внимательное отношение к проживающим; содействие в улучшении качества жизни проживающих». И на крайние случаи - это «адлинистративные меры (штрафы, выговоры, перевод в другие учреждения».

Какие в последнее время появились инновации в технологиях социальной работы с обслуживаемыми в доме-интернате? Эксперты назвали следующие направления инновационных введений: «ретро-терапия - прослотр старый фильмов и прослушивание старых мелодий, изотерапия, занятия по мелкой моторике и др.».

Как известно, для внедрения различных инноваций, создания новых направлений работы требуется финансовое вложение. Следовательно, одним из вопросов экспертного интервью специалистов учреждения был: «Осуществляется ли материальная поддержка работы дома-интерната со стороны спонсоров?». В результате опроса, 75 \% специалистов отметили, что поддержка осуществляется, и $25 \%$ сотрудников затруднились с ответом. Следует отметить, что никто из специалистов не ответил отрицательно, значит сторонние организации оказывают действенную помощь интернату. Респонденты, которые ответили «да», уточнили в каком виде оказывают материальную помощь: «в натуральном виде: ткань, конфеты», "дарят подарки получателям социальных услуг», "полощь оказывают часто», "материальная помощь по праздникам в виде продуктов, средств гигиены», "проведение концертов, чаепитие в актовом зале», "в материально бытовых условиях и денежных», «пожертвования», «не регулярно, от случая $\kappa$ случаю, поставка мягкого инвентаря, товаров, услуги или работы».

Проведенное социологическое исследование включало анкетный опрос проживающих в доме-интернате, ознакомление с их мнением относительно условий проживания в учреждении, социальной адаптации их в доме-интернате. В ходе исследования было опрошено 50 человек из числа постоянно и временно находящихся на социальном обслуживании в учреждении, в т. ч. пожилые люди и инвалиды до пенсионного возраста. [3;4]

На вопрос «Как Вы оцениваете социальную помощь, которую Вам оказывают в доме-интернате» по результатам опроса 2005 г. большинство опрошенных ответили положительно и оценили эту помощь «хорошо». Удовлетворительную оценку дала пятая часть респондентов, и только 6,1 \% позволили себе оценить социальную помощь интерната как плохую.

В 2017 г. были получены следующие результаты: почти половина респондентов посчитали степень оказания социальной помощи на хорошем уровне, примерно столько же респондентов ответили, что социальная помощь оказывается удовлетворительно, 8 \% - дали оценку «плохо».

В целом, можно сказать, что показатели идентичные при сравнении двух периодов проведения исследования.

Оценка проживающили качества социальной помощи, оказываемой в домах-интернатах, \%

\begin{tabular}{|l|r|r|}
\hline \multicolumn{1}{|c|}{ Варианты ответов } & \multicolumn{1}{|c|}{2005} & \multicolumn{1}{c|}{2017} \\
\hline Хорошо & 78,7 & 46,0 \\
\hline Удовлетворительно & 12,8 & 44,0 \\
\hline Плохо & 6,4 & 8,0 \\
\hline Затрудняюсь ответить & 2,1 & 2,0 \\
\hline
\end{tabular}

Какие положительные и отрицательные стороны пребывания в Доме-интернате Вы находите? На данный вопрос были получены разные ответы пожилых и инвалидов, проживающих в доме-интернате. В частности, «все хорошо, претензий нет», «все нравится, за нали ухаживают, все устраивает»; «мало развлечений»; «медобслу-

\section{Baikal Research Journal}

электронный научный журнал Байкальского государственного университета 
живание и работа медицинского персонала оставляет желать лучшего»; «если нужно отвезут, куда необходило»; «зависилость от других»; «нельзя пообщаться c персоналом»; «тяжелый народ вокруг»; «все хорошо, кроле медицинского обслуживания»; «нет тренажеров для инвалидов-колясочников, нет спортивной площадки»; «бытовые условия хорошие»; «главный врач редко делает обход, его нет по несколько месяцев»; «хорошо готовят, создают бытовые условия», и пр.

Главная из проблем проживающих, выявленная по данному вопросу — тяжелое психологическое состояние, недостаток общения, ощущение одиночества, невозможность найти «поддержку, общение, понимание со стороны работников; отношение со стороны персонала слишкол форлализованное, неучастливое».

Что не устраивает пожилых, инвалидов в условиях проживания и социального обслуживания в домах-интернатах?

Среди опрошенных постояльцев дома-интерната $16 \%$ не устраивает техническое оснащение и возможности оказания медицинской помощи, больше жаловались на медицинскую помощь; $14 \%$ - не нравится качество обслуживания и лечения; по $12 \%$ респондентов выбрали питание и бытовые условия, взаимоотношения с другими проживающими, отношение обслуживающего и медицинского персонала. Остальные же респонденты указали другие причины $(64 \%)$ : «все устраивает», «все хорошо», «все на удовлетворительнол уровне», «теснота», «все нравится».

Как можно отметить, за исследуемый период - с 2005 по 2017 гг. - проблемы качества питания, бытового обслуживания уходят, но первостепенное значение приобретают проблемы взаимоотношений между проживающими.

Таблица 5

Распределение ответов на вопрос: “Что Вас, прежде всего, не устраивает в проживании в Доме-интернате?", \%

\begin{tabular}{|l|r|r|}
\hline \multicolumn{1}{|c|}{ Варианты ответов } & \multicolumn{1}{c|}{2005} & \multicolumn{1}{c|}{2017} \\
\hline Отношение обслуживающего и медицинского персонала & 4,3 & 12,0 \\
\hline Взаимоотношения с другими проживающими & 2,1 & 12,0 \\
\hline Качество обслуживания и лечения & - & 14,0 \\
\hline Питание, бытовые условия & 23,4 & 12,0 \\
\hline Техническое оснащение, возможности оказания медицинской помощи & 4,3 & 16,0 \\
\hline
\end{tabular}

Часты конфликты между проживающими. Есть проблема проживания лиц с алкоголизмом, вследствие этого страдают непьющие проживающие (выслушивают маты, терпят нарушения порядка и прочее). Например, одной из рекомендаций со стороны проживающих было: «нужно создать отдельное полещения для mex, кто выпивает». Одной из важнейших проблем отмечается то, что в комнатах проживают «психологически несовместимые граждане», либо «физически несовместимые».

C какими проблемами в первую очередь сталкиваются обслуживаемые впервые попавшие в данное учреждение? Ответы респондентов выявили следующие проблемы: «адаптация $\kappa$ новому месту, к новым людям, $\kappa$ новому порядку»; «много людей вокруг, а внилания мало»; «плохой воздух»; "возникают конфликты с проживающими более длительный период»; «невнилательность некоторых работников»; «стрессы, сплетни, трудности в отношениях между проживающили»; «психологические проблель, конфликтность».

Исследовалось также наличие и особенности взаимопомощи обслуживаемых друг другу в процессе адаптации к условиям проживания в домах-интернатах. «Помогают ли постояльцы адаптироваться к условиям дома-интерната вновь прибывшим?». По данным опроса проживающих, 72 \% респондентов дали положи-

\section{Baikal Research Journal}

электронный научный журнал Байкальского государственного университета 
тельный ответ, в то время как 28 \% ответили отрицательно. Те, кто ответил положительно, рассказывают, что «полощь оказывают, если попросить», «общаются с прибывшили», «помогают во всел», «морально поддержали, тепло приняли», «дают денег, еду, вещи», «пологают передвигаться», "в магазин сходят», "проводят, куда надо», подсказывают, дают советы» и др.

Были даны ответы о том, что помощь заключается в основном в моральной поддержке. Например, «дать наставление, советы вновь прибывшим в интернат, поддержать в конфликтной ситуации, провести беседу». Кроме того, некоторые отмечают, что «по мере возможности помогают проживающим, у которых проблелы с салостоятельными передвиженияли; помогают обслуживать себя».

Относительно питания в столовой интерната проживающих «устраивает все; норлальное питание». Такие ответы в большинстве. Но, есть и пожелания: «хочется больше разнообразия, больше кисломолочных продуктов, свиного мяса, овощей и фруктов, побольше стряпанного».

Одним из важнейших факторов, определяющих социально-психологическую адаптацию проживающих в домах-интернатах, является характер взаимоотношений проживающих с персоналом учреждения и между собой. [5]

Если рассматривать взаимоотношения проживающих с персоналом дома-интерната (медицинские работники, социальные работники, психологи и другие), то больше половины респондентов считают, что отношения с персоналом складываются хорошие; треть считает, что отношения с работниками у них удовлетворительные, и 6 \% затруднились ответить. Следует отметить, что ни у кого из опрошенных нет плохих отношений с персоналом.

В сравнении с результатами опроса 2005 г. в настоящее время ситуация незначительно изменилась, общая оценка удовлетворенности взаимоотношениями проживающих с работниками дома-интерната осталась по-прежнему высокой. Около $96 \%$ респондентов из числа обслуживаемых полагают, что такие отношения «хорошие или удовлетворительные». Оценку «плохие взаимоотношения» ни в 2005 г., ни в 2017 г. никто не давал.

Распределение ответов на вопрос: "Какие у Вас взаимоотношения с медперсоналом и социальными работниками дома-интерната?», \%

\begin{tabular}{|l|r|r|}
\hline \multicolumn{1}{|c|}{ Варианты ответов } & \multicolumn{1}{c|}{2005} & \multicolumn{1}{c|}{2017} \\
\hline Хорошие & 85,1 & 64,0 \\
\hline Удовлетворительные & 10,6 & 30,0 \\
\hline Плохие & - & - \\
\hline Затрудняюсь ответить & 4,3 & 6,0 \\
\hline
\end{tabular}

Исследование позволяет охарактеризовать и взаимоотношения между проживающими, выявить основные проблемы, причины конфликтов среди них. Согласно данным интервью в среднем большинство опрошенных, как в 2005 г., так и в 2017 г. проведения опроса, характеризуют отношения между проживающими домов-интернатов как очень хорошие и удовлетворительные. Респондентов, давших оценку «удовлетворительно» в 2017 г. гораздо больше, чем в 2005 г., при этом меньше доля тех, кто оценивает отношения проживающих друг с другом высокой оценкой. Только отдельные лица отметили, что у них выстраиваются плохие взаимоотношения с соседями по интернату (2\%).

Какие же в частности существуют сложности взаимоотношений между проживающими в интернатах? Например, «соседка не разрешает слотреть ТВ», «не обращают друг на друга внилание», «все люди разнье, тяжело», «люди разные и

\section{Baikal Research Journal}

электронный научный журнал Байкальского государственного университета 
с каждым найти общий язык сложно», «трудно найти общий язык, у всех свои проблель, возраст» .

Распределение ответов на вопрос: «Какие у Вас взаимоотношения с другими проживающими дома-интерната?", \%

\begin{tabular}{|l|r|r|}
\hline \multicolumn{1}{|c|}{ Варианты ответов } & 2005 & \multicolumn{1}{c|}{2017} \\
\hline Хорошие & 87,2 & 54,0 \\
\hline Удовлетворительные & 6,4 & 40,0 \\
\hline Плохие & 2,1 & 2,0 \\
\hline Затрудняюсь ответить & 2,1 & 4,0 \\
\hline
\end{tabular}

Очень важным фактором социально-психологической адаптации проживающих в домах-интернатах является возможность проведения свободного времени в плане развлечений и реализации своих профессиональных способностей.

В результате анализа ответов на вопрос «Как Вы оцениваете условия для интересного досуга, развлечений в Доме-интернате?» в 2017 г. выяснилось, что основная часть респондентов (62\%) ответила, что условия для интересного досуга в интернате хорошие, $16 \%$ респондентов посчитали условия удовлетворительными, $12 \%$ опрошенных затруднились ответить и $10 \%$ респондентов не устроили условия для интересного досуга.

Таблица 8

Распределение ответов на вопрос: «Как Вы оцениваете условия для интересного досуга, развлечений в доме-интернате?», \%

\begin{tabular}{|l|r|r|}
\hline \multicolumn{1}{|c|}{ Варианты ответов } & 2005 & \multicolumn{1}{|c|}{2017} \\
\hline Хорошие & 85,1 & 62,0 \\
\hline Удовлетворительные & 8,5 & 16,0 \\
\hline Плохие & - & 10,0 \\
\hline Затрудняюсь ответить & 2,1 & 12,0 \\
\hline
\end{tabular}

Среди возможностей проведения свободного времени проживающие перечислили следующее: «библиотека, игра в шахлаты и шашки, игра в карты, прослотр телевизора как наиболее распространенная практика проведения досуга у большинства; игра в бильярд, различные кружки по вязанию, шитью и вышиванию; прослушивание радио». Некоторые молодые проживающие в интернате часто пользуются тренажерным залом и занимаются спортом, либо просто гимнастикой [6].

Отдельные пожилые отмечают, что им нравится заниматься садоводством, цветоводством, выращиванием овощей, они бы с удовольствием этим занимались, если бы была такая возможность на территории дома-интерната. Практику работы на огороде многие рассматривают не как способ получения дополнительных продуктов питания и как вид трудовой деятельности, а скорее как развлечение. Многие из проживающих кормят голубей.

Среди большинства проживающих распространено участие в хоровых пениях, танцах, художественной самодеятельности, организации театральных сценок, концертов. Многие сами играют на различных инструментах (баяне, гармошке и пр.). Любят проживающие и совместно отмечать праздники, дни рождения.

Основным же способом проведения досуга для большинства является просмотр телевизионных программ и чтение книг, а также прогулки по улице, поездки в гости к родственникам, друзьям. Иногда проводятся экскурсии. Так, вспоминают выезд в Тальцы. Проводятся экскурсии в театры и музеи города, но редко 2 .

${ }^{2}$ Государственная долгосрочная социальная программа «Старшее поколение» на 2014-2018 гг. URL: http://irkobl.ru/sites/society/programs/gos_programm_irk_obl.

\section{Baikal Research Journal}

электронный научный журнал Байкальского государственного университета 
Возможности для реализации профессиональных знаний оценивают как достаточные $44,7 \%$ проживающих, как неудовлетворительные $-28,5$ \% и ничего не знают о таких возможностях 26,8 \% обслуживаемых (по даннным опроса 2005 г.). К тому же далеко не все могут заниматься трудотерапией по состоянию здоровья. Но те, кто этим все же пользуется (таких 12 \%), выполняют следующие виды работ: работа вахтерами, сторожами, дворниками, уборщиками; работа в столовой, на кухне; столярами, плотниками, слесарями, лифтерами; работа в швейном цехе, работа в прачечной; работа в библиотеке, работа по организации художественной самодеятельности и прочее. Работа на приусадебных участках по выращиванию овощей, ягод, разведению цветов временно не доступна в учреждении.

Также проживающие занимаются рукоделием (вышивка, макраме), изготовлением поделок, сувениров не только для развлечения, в отдельных случаях и для продажи. Есть такой вид «должности» среди проживающих, как староста, следящий за порядком [7;8].

На вопрос о том, есть ли у Вас возможность проводить свое свободное время за пределами дома-интерната, половина респондентов ответили, что «да и они этим часто пользуются»; треть респондентов отметили, что такая возможность есть, но они не пользуются этим; 18 \% отметили, что такая возможность у них затруднена.

Оценка возможностей проводить свободное время за пределами

Таблица 9 дома-интерната, \%

\begin{tabular}{|l|r|r|}
\hline \multicolumn{1}{|c|}{ Варианты ответов } & 2005 & \multicolumn{1}{c|}{2017} \\
\hline Да, и я часто этим пользуюсь, например & 29,8 & 32,0 \\
\hline Да, но я этим не пользуюсь & 19,1 & 50,0 \\
\hline Такая возможность затруднена & 6,4 & 18,0 \\
\hline
\end{tabular}

Возможности для проведения свободного времени за пределами домаинтерната многими рассматриваются как недостаточные. Однако, в сравнении с домами-интернатами, располагаемыми за пределами города, больше всего такой возможностью пользуются обслуживаемые в Ново-Ленинском интернате: ездят в гости, к родственникам, за продуктами в магазин, на рынок, просто прогуливаются по городу. Некоторые ездят в другие города к родственникам, на свои дачные участки. Например, были получены ответы: «езжу в магазины, гулять в городе, на досуговые развлечения, к брату в гости, домой к родственникам в Ангарск, Тулун, Зиму и пр.». Проблема в том, что такая возможность затруднена в связи со здоровьем, с трудностью передвижения. К тому же для выезда необходимы и финансовые средства.

Анализ ответов на вопрос «Как часто Вас посещают родственники?» дал следующую статистику в 2017 г.: $32 \%$ респондентов родственники посещают изредка, $26 \%$ не посещают совсем, $24 \%$ респондентов встречаются со своими близкими редко и только $18 \%$ опрошенных посещают регулярно.

Таблица 10

Частота посещения родственниками проживающих дома-интерната, \%

\begin{tabular}{|l|r|r|}
\hline \multicolumn{1}{|c|}{ Варианты ответов } & \multicolumn{1}{c|}{2005} & \multicolumn{1}{c|}{2017} \\
\hline Регулярно & 17,1 & 18,0 \\
\hline Изредка & 4,3 & 32,0 \\
\hline Редко & 10,6 & 24,0 \\
\hline Не посещают совсем & 21,3 & 26,0 \\
\hline
\end{tabular}

\section{Baikal Research Journal}

электронный научный журнал Байкальского государственного университета 
Как видно, с течением последних 12 лет родственники пожилых и инвалидов, проживающих в доме-интернате, стали гораздо реже посещать своих родных. Частота выбора таких вариантов ответов, как «изредка и редко» возросла в 2017 г. в сравнении с данными опроса 2005 г. Но, почти не изменилась доля «совсем не посещаемых родственниками» пожилых и инвалидов дома-интерната. Также остается с течением времени неизменной доля проживающих, «регулярно посещаемых своими родными и близкими». [9]

О качестве социального обслуживания в домах интернатах косвенно свидетельствуют желания проживающих уехать из интерната или продолжать в нем жить. По свидетельствам проживающих Ново-ленинского дома-интерната, им очень нравится жить в доме-интернате и они считают, что дома им было бы гораздо труднее: «мне здесь хорошо, жила в частном доме, там тяжело и страшно».

Почему не собираются возвращаться домой? В большинстве случаев, т.к. пожилые не в состоянии жить одни дома, либо дома вообще нет, а некоторые просто отмечают, что «здесь лучше, чел дома».

Таблица 11 Распределение ответов на вопрос: “Собираетесь ли Вы возвращаться домой?», \%

\begin{tabular}{|l|r|r|}
\hline \multicolumn{1}{|c|}{ Варианты ответов } & 2005 & \multicolumn{1}{|c|}{2017} \\
\hline Собираюсь возвращаться домой & 4,3 & - \\
\hline Не собираюсь уезжать домой & 82,9 & 94,0 \\
\hline Пока не решил & 4,3 & 6,0 \\
\hline
\end{tabular}

В вопросе «Собираетесь ли Вы возвращаться домой?» почти все респонденты исследования и 2005 г. и 2017 г. выбрали вариант «нет», и лишь 4-6 \% ответили, что пока не знают. Абсолютно никто в 2017 г. не выразил своего желания покинуть дом-интернат. Можно сделать вывод, что люди, находясь в доме-интернате, даже не рассматривают вариант возвращения домой и готовы провести всю оставшуюся жизнь в интернате.

Из тех немногих проживающих, кто пока не решил, возвращаться домой или нет, отмечаются следующие причины возвращения. Либо их не устраивают условия проживания в интернате и у них есть возможность вернуться домой (сын или дочь приедут и заберут); либо поселение было временное на период «пережить определенный этап жизни». Выяснилось, что некоторые пожилые выражают заблуждения относительно приезда их детей (внуков) и того, что дети их заберут домой.

Таким образом, учитывая все аспекты социально-психологической адаптации проживающих к условиям дома-интерната, обозначим основные рекомендации по улучшению условий стационарного социального обслуживания, предложенные самими проживающими данных учреждений. Одно из значимых пожеланий - приобрести автобус для инвалидов, чтобы обеспечить возможность им выезжать на прогулки и экскурсии вместе с остальныли проживающили. Есть пожелания обратить внилание на разнообразие форл досуга. Относительно лечения все высказываются по поводу того, что лекарствали дом-интернат должен обеспечивать полностью или хотя бы в больщей мере, поскольку салим приобретать лекарства, необходимые для неотложного лечения, у проживающих нет средств. Есть замечание относительно того, что лечить стараться нужно «на месте», не отправляя в больницы.

Наиболее часто встречается рекомендация обслуживаемых выделять больше средств на совершенствование технического оснащения ледииинских кабинетов (приобретать новое медицинское оборудование, аппаратуру, учитывая новые технологии медицинского обслуживания). Проживающие отмечают то, что не

\section{Baikal Research Journal}

электронный научный журнал Байкальского государственного университета 
обеспечивается их законное право на лечение в санаториях, на курортах. Также отмечается, что следовало бы обеспечивать проживающих в домах-интернатах хозяйственныли принадлежностяли (мылом, стиральным порошком и пр.), необходимым инвентарем.

Бытует мнение среди проживающих домов-интернатов о том, что больше финансовых средств домам-интернатам следует выделять «на улучшение социального и медииинского обслуживания, повышение качества питания, а не на проведение евроремонта». На их взгляд, конечно необходимо в помещении домов-интернатов проводить капитальный и косметический ремонт, но без излишеств. Например, «евроремонт» для них особо значения не представляет, им было бы полезнее приобретение одежды, инвалидных колясок, ортопедических приборов, медицинского оборудования, дорогостоящих лекарств и пр.

Пожелание обратить внимание на качество приготовления пищи, на разнообразие блюд. Поскольку даже из имеющего ассортимента продуктов питания можно разнообразнее и качественнее готовить пищу.

Всеми опрашиваемыми повторяется мнение о необходимости уделения большего внимания борьбе с алкоголизмом в стационарах, а также вопросу расселения проживающих в соответствии с возрастом, состоянием здоровья и психологическими особенностями. Например, такие высказывания: «Работу вести против пьянства и курения. Создать курилки и наказывать за нецензурную брань»; "Раздельно содержать инвалидов и престарелых, не выключать горячую воду».

Есть рациональное предложение увеличить количество телевизоров на этаже, поскольку зачастую причиной конфликтов между проживающими выступают споры по поводу того, какую телевизионную программу просматривать. Наблюдается нехватка радио в комнатах, что особенно неблагоприятно влияет на психологическое самочувствие «лежачих" больных, т.к. радио для них по сути единственный способ связи с окружающим миром.

Проживающие просят создать тренажерный зал, спортзал и теннисный корт. Один из проживающих внес рациональное предложение привлекать помощь спонсоров, особенно при проведении праздников в домах-интернатах. В целом необходимо «больше интересоваться жизнью проживающих», не только форлально подходить к обслуживанию граждан».

\section{Список использованной литературы}

1. Стратегия социальной защиты населения крупного сибирского города (на основе социолого-статистических исследований системы социальной защиты населения г. Иркутска) / ред. В. И. Самаруха, Б. Л. Токарский. - Иркутск: Изд-во БГУЭП, 2011. - 205 с.

2. Токарский Б. Л. Формирование условий жизни граждан пожилого возраста и инвалидов в учреждениях стационарного социального обслуживания (по результатам социологического исследования в г. Иркутске) / Б. Л. Токарский, Е. И. Нефедьева // Уровень жизни и социальная поддержка населения : материалы круглого стола, 28 февраля 2006 г. Иркутск : Изд-во БГУЭП, 2006. - С. 35-43.

3. Карпикова И. С. Показатели функционирования системы социальной защиты в аспекте оценки качества жизни населения / И. С. Карпикова // Известия ИГЭА. 2011. - № 3. - С. $175-178$.

4. Качество жизни населения крупного сибирского города: оценка современного состояния и возможные пути его повышения (по результатам социологических исследований в городе Иркутске) / под науч. ред. Н. Н. Даниленко, И. С. Карпиковой. - Иркутск : Издво БГУЭП, 2014. - 236 с.

5. Максимова С. Г. Социально-психологическая адаптация: особенности формирования и развития у лиц пожилого и старческого возраста / С. Г. Максимова. - Барнаул : Изд-во Алт. ун-та, 2012. - 145 с.

\section{Baikal Research Journal}

электронный научный журнал Байкальского государственного университета 
6. Киселева Н. А. Люди пожилого возраста как объект социальной работы / Н. А. Киселева // Научно-методический электронный журнал «Концепт». — 2016. — № 1 (январь). - С. 31-35.

7. Инкижинова С. А. Инновационные технологии социальной защиты пожилых людей: учеб. пособие / С. А. Инкижинова. - Иркутск : Изд-во БГУЭП, 2009. - 60 с.

8. Иванов А. В. Инновационные процессы в системе реабилитации инвалидов: автореф. дис.... канд. социол. наук / А. В. Иванов - М., 2010. - 20 с.

9. Корнилова М. В. Особенности социального обслуживания граждан пожилого возраста и инвалидов / М. В. Корнилова // Социологические исследования. - 2011. — № 8 (328). C. 34 .

\section{References}

1. Samarukha V. I., Tokarskii B. L. (eds). Strategiya sotsial'noi zashchity naseleniya krupnogo sibirskogo goroda (na osnove sotsiologo-statisticheskikh issledovanii sistemy sotsial'noi zashchity naseleniya g. Irkutska) [Strategy of social protection for a major Siberian city's townspeople (on the basis of sociological and statistical investigations of social protection system for Irkutsk citizens]. Irkutsk, Baikal State University of Economics and Law Publ., 2011. 205 p.

2. Tokarskii B. L., Nefed'eva E. I. Developing of living conditions for the aged and disabled in social service institutions (based on the results of sociological studies in Irkutsk). Uroven' zhizni $i$ sotsial'naya podderzhka naseleniya : materialy kruglogo stola, 28 fevralya 2006 g. [Living standard and social support: Materials of Round Table, February 28, 2006]. Irkutsk, Baikal State University of Economics and Law Publ., 2006, pp. 35-43. (in Russian).

3. Karpykova I. S. Indicators of functioning of social protection system in terms of evaluating people's quality of life. Izvestiya Irkutskoi gosudarstvennoi ekonomicheskoi akademii = Bulletin of Irkutsk State Economic Academy, 2011, no. 3, pp. 175-178. (in Russian).

4. Danilenko N. N., Karpikova I. S. (eds). Kachestvo zhizni naseleniya krupnogo sibirskogo goroda: otsenka sovremennogo sostoyaniya i vozmozhnye puti ego povysheniya (po rezul'tatam sotsiologicheskikh issledovanii $v$ gorode Irkutske) [Quality of living of a major Siberian city's townspeople: evaluation of current state and possible ways of its increasing (based on the results of social studies in Irkutsk city)]. Irkutsk, Baikal State University of Economics and Law Publ., 2014. 236 p.

5. Maksimova S. G. Sotsial'no-psikhologicheskaya adaptatsiya: osobennosti formirovaniya $i$ razvitiya $u$ lits pozhilogo $i$ starcheskogo vozrasta [Socio-psychological adaptation: features of the aged and old-aged people' formation and development]. Barnaul, Altaiskii universitet, 2012. $145 \mathrm{p}$.

6. Kiseleva N. A. The aged people as an object of social work. Nauchno-metodicheskii elektronnyi zhurnal "Kontsept» = Scientific and Methodical Journal "Concept», 2016, no. 1. pp. 31-35. (in Russian).

7. Inkizhinova S. A. Innovatsionnye tekhnologii sotsial'noi zashchity pozhilykh lyudei [Innovative technologies in social protection of the aged]. Irkutsk, Baikal State University of Economics and Law Publ., 2009. 60 p.

8. Ivanov A. V. Innovatsionnye protsessy $v$ sisteme reabilitatsii invalidov Avtoref. Kand. Diss. [Innovative processes in system of rehabilitation of the disabled. Cand. Diss. Thesis]. Moscow, 2010. $20 \mathrm{p}$.

9. Kornilova M. V. Features of social service for the aged and disabled citizens. Sotsiologicheskie issledovaniya = Sociological Studies, 2011, no. 8 (328), pp. 34. (in Russian).

\section{Информация об авторах}

Нефедьева Елена Ивановна - кандидат экономических наук, доцент, кафедра социальной и экономической психологии, социологии и социальной работы, Байкальский государственный университет, г. Иркутск, 664003, г. Иркутск, ул. Ленина, 11, e-mail: nei10@ mail.ru.

Кудрявцев Сергей Иванович - магистрант направления «Социальная работа», Байкальский государственный университет, г. Иркутск, 664003, г. Иркутск, ул. Ленина, 11, e-mail: harat_1960@mail.ru.

\section{Baikal Research Journal}




\section{Authors}

Yelerna I. Nefedyeva - Ph.D. in Economics, Associate Professor, Chair of Social and Economic Psychology, Sociology and Social Work, Baikal State University, 11 Lenin St., 664003, Irkutsk; e-mail: nei10@mail.ru.

Sergey I. Kudryavtsev - Master Degree Student in Social Work, Baikal State University, 11 Lenin St., 664003, Irkutsk; e-mail: harat_1960@mail.ru.

\section{Для цитирования}

Нефедьева Е. И. Социально-экономическая адаптация граждан пожилого возраста и инвалидов в стационарных условиях социального обслуживания (на примере ОГБУСО «Ново-Ленинский дом-интернат для престарелых и инвалидов») / Е. И. Нефедьева, С. И. Кудрявцев // Baikal Research Journal. - 2017. — Т. 8, № 3. - DOI : 10.17150/2411$6262.2017 .8(3) .26$.

\section{For Citation}

Nefedyeva Ye. I., Kudryavtsev S. I. Social and economic adaptation of the aged citizens and disabled in stationary environment of social service (in terms of «Novo-Lenino Care Home for the Aged and Disabled». Baikal Research Journal, 2017, vol. 8, no 3. DOI : 10.17150/24116262.2017.8(3).26. (In Russian).

\section{Baikal Research Journal}

